\title{
Autonomic nervous system evaluation in Type 2 diabetic patients and effect of its duration
}

\author{
Karki DB ${ }^{1}$, Acharya $\mathrm{S}^{2}$, Shrestha $\mathrm{P}^{3}$, Pant $\mathrm{S}^{2}$, Pokhrel A4, Bista $\mathrm{P}^{5}$ \\ ${ }^{1}$ Professor, ${ }^{2}$ Residents, ${ }^{3}$ Intern, ${ }^{4}$ Lecturer, ${ }^{5}$ Medical Officer \\ Department of Medicine, Kathmandu Medical College Teaching Hospital, Kathmandu, Nepal
}

\section{Abstract}

Introduction: Dysfunction of the autonomic nervous system is common in diabetic patients. Presence of autonomic dysfunction should alert the physicians of its serious consequences that require timely preventive measures.

Objectives: This study was done to find out the autonomic nervous system involvement in Type 2 diabetic patients and to see its relation with the duration of diabetes.

Methods: This was a hospital based cross-sectional study. All consecutive diabetic patients of both genders attending Kathmandu Medical College and a private clinic, Temple of Healing were included. A battery of six well validated and accepted autonomic nervous system evaluation tests were done to evaluate the autonomic function in 245 Type 2 diabetic patients.

Results: Prevalence of autonomic dysfunction was found to be $71.02 \%$ with $58.78 \%$ patients having mild autonomic dysfunction and $12.24 \%$ having moderate dysfunction. Severe autonomic dysfunction was detected in none of the patients. Parasympathetic dysfunction was much more common than sympathetic dysfunction (68.16\% vs. $17.96 \%)$. No association was found between autonomic dysfunction and duration of diabetes.

Conclusions: Autonomic dysfunction is very common in diabetics and can be detected by simple tests. Timely detection of autonomic dysfunction in diabetic patients is advised so that its preventive measures can be effective.

Key words: Autonomic nervous system dysfunction, Type 2 diabetes mellitus, Valsalva Ratio

\section{INTRODUCTION}

Tany clinical conditions have been found to be the 1 cause of autonomic dysfunction and diabetes mellitus may be considered as one of the most common causes ${ }^{1}$. According to Steno Type 2 Trials, nearly $28 \%$ of Type 2 diabetic patients have been found to have autonomic dysfunction ${ }^{2}$. As a result of sympathetic over-activity and prolonged QT interval, ventricular arrhythmias may result in sudden death ${ }^{3}$.

According to a publication in Diabetes Review in 1999 by $D$ Ziegler, the mortality of autonomic neuropathy free subjects over 5.5 years has been found to be approximately five percent but this increased to 27 percent with the onset of abnormal cardiovascular reflex tests ${ }^{4}$. In patients with Type 2 diabetes mellitus enrolled in the longitudinal Appropriate Blood Pressure Control in Diabetes (ABCD) trial, cardiovascular

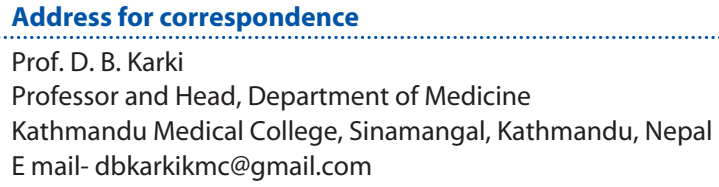

autonomic neuropathy was an independent risk factor for the occurrence of stroke 5 . In obese subjects, diabetic autonomic nervous dysfunction has been found to be associated with an increased risk of obstructive sleep apnoea as compared to other obese subjects without diabetes ${ }^{6}$.

Common symptoms of autonomic neuropathies are fainting episodes due to postural hypotension, erectile dysfunction in men, urinary incontinence, dyspepsia and constipation. Supine hypertension at night has been reported in Type 2 diabetes mellitus ${ }^{7}$. Twenty four hour ambulatory blood pressure monitoring usually reveals fall in blood pressure at night. In occasional patients with diabetes, supine and standing systolic blood pressure may fall profoundly after meals ${ }^{8}$. Diabetic foot is one of the common complications of diabetes mellitus. Peripheral autonomic neuropathy may be a pre-requisite for the development of foot ulceration ${ }^{9,10}$. Sympathomimetic drugs have a beneficial effect on pedal oedema ${ }^{11}$. Diabetic patients with pupillary abnormalities have difficulty driving at night. 
It is obvious that presence of autonomic dysfunction increases morbidity and mortality in diabetes. Early detection of such dysfunction is a must to prevent complications. Strict control of blood sugar can prevent progression of this condition.

This study was done to find out the autonomic nervous system involvement in Type 2 diabetic patients and to see its relation with the duration of Diabetes.

\section{METHODS}

This hospital based cross-sectional study was conducted among the diabetic patients visiting the department of Medicine of Kathmandu Medical College Teaching Hospital and a private clinic, Temple of Healing, from August 2009 to the end of August 2011. All consecutive Type 2 diabetes mellitus patients of both genders willing to undergo tests for autonomic dysfunction were included. A total of two hundred and forty five patients underwent tests for autonomic nervous dysfunction. The details of autonomic nervous system evaluation tests (ANSEV) are given below:

\section{TESTS OF PARASYMPATHETIC DYSFUNCTION}

Resting Heart Rate (RHR): Resting heart rate $>100 /$ minute was taken as a positive test for the involvement of parasympathetic nervous system. Resting heart rate was calculated from an electrocardiogram (ECG). Normally heart rate varies from 60 to 100 beats per minute.

Heart rate variation in deep expiration and inspiration (HEXIN) ${ }^{12}$ : Heart rate variation with respiration is another test of parasympathetic nervous system. After deep breathing at a rate of six breaths per minute, heart rates during expiration and inspiration were calculated with help of an ECG. Heart rate variability of $<10$ beats per minute was considered positive test. Normally heart rate increases during inspiration and decreases during expiration. The respiratory variation of heart rate is known to decrease with advancing age $^{13}$. Tests of heart rate variability with deep breathing are performed in supine position where vagal tone is greatest ${ }^{14}$. The maximal heart rate response in subjects with autonomic neuropathy occurs at lower respiratory rate $\mathrm{r}^{15,16}$.

Heart rate response to standing: The heart rate changes on standing were recorded on an ECG and expressed as the ratio between the $30^{\text {th }}$ beat and $15^{\text {th }}$ beat in the ECG. The 30:15 RR interval (RRI) and its ratio (RRIR) of less than one was considered abnormal ${ }^{11}$. In normal individuals, acceleration of the heart rate is maximal up to 15 beats after standing and slows to near supine rate at 30 beats. Failure of the heart rate to increase is indicative of autonomic dysfunction.

Valsalva ratio (VR): The Valsalva manoeuvre was performed by closing the nose and asking the patient to maintain the column of mercury in the Sphygmomanometer at $40 \mathrm{mmHg}$ by blowing through the rubber tube for 15 seconds. Valsalva ratio i.e. heart rate variability after and during valsava, of $<1.1$ was considered positive ${ }^{12}$. Valsalva ratio is commonly used to assess the autonomic nervous system evaluation. As forced expiration is continued mean arterial and pulse pressure decrease then the heart rate increases. After the release of Valsalva, the cardiac output and blood pressure increase resulting in reflex bradycardia. Normally, ratio of RR interval after Valsalva and during Valsalva (VR) is $\geq 1.1$. As the heart rate does not increase during Valsalva in autonomic dysfunction, the Valsalva ratio becomes $<1.1$.

\section{TESTS OF SYMPATHETIC DSYFUNCTION}

Presence of Postural Hypotension: Blood pressure was recorded during supine position and after three minutes of standing. A fall of systolic blood pressure of more than $20 \mathrm{mmHg}$ was considered to be due to postural hypotension.

Hand-Grip Response: Person undergoing hand grip test (HGT) required to maintain maximal handgrip for three minutes. If diastolic blood pressure rise was less than $10 \mathrm{mmHg}$ or heart rate rise less than 10 beats per minute, the test was considered positive ${ }^{12}$. Normally the diastolic BP increase is more than $10 \mathrm{mmHg}$ and heart rate rises by more than 10 beats per minute after maximum hand grip for three minutes ${ }^{12}$.

Autonomic nervous dysfunction was graded as Mild (One or two tests positive), Moderate (three or four or five tests positive), Severe (all tests positive) and Normal (all tests normal).

Presence of Autonomic dysfunction was compared with different variables like hypertension, smoking, lipid levels and BMI. It was also compared with the duration of diabetes and results expressed as duration less than five years, more than five years, less than 10 years and more than 10 years.

Patients taking antihypertensive treatment for hypertension or those with systolic blood pressure of $\geq 140 \mathrm{mmHg}$ and diastolic blood pressure of $\geq 90 \mathrm{mmHg}$ 
were considered to be hypertensive. Those patients who were currently smoking or had stopped smoking for less than four weeks were considered as smokers in this study. Similarly, those who consume alcohol or had stopped consuming alcohol for less than four weeks were considered alcohol consumers. BMI $\geq 25 \mathrm{~kg} / \mathrm{m}^{2}$ was taken as overweight.

All patients' data were entered in the Statistical Package for Social Sciences (SPSS) 16 statistical package. Comparison was done by calculating $p$ value by $\mathrm{Chi}$ square tests or the paired t test as applicable. A p value of $<0.05$ was considered statistically significant. For study of relation of autonomic dysfunction with duration of the disease, arbitrary cut-off points of five and 10 years were chosen and association between those respective durations with occurrence of autonomic dysfunction was tested by chi-square test.

\section{RESULTS}

\section{BASELINE VARIABLES}

The tests of autonomic dysfunction were performed in 245 Type 2 diabetes mellitus patients. The baseline variables categorised into duration of the disease less than five years and more than five years are presented in Table 1.

The mean age of the patients was 56 years (standard deviation, SD: 11 years) with a minimum age 28 years and maximum age 84 years. The baseline variables were comparable ( $p>0.05)$ among the two groups as shown in Table 1.
Among the 245 patients evaluated, 164 (66.94\%) were hypertensives, 35 (14.29\%) were smokers, 58 (23.57\%) were alcohol consumers and $136(55.51 \%)$ had $\mathrm{BMI} \geq 25$ $\mathrm{kg} / \mathrm{m}^{2}$. Regarding lipid profile, total cholesterol (TC) was high ( $\geq 200 \mathrm{mg} / \mathrm{dL}$ ) in 58 (23.67\%), triglycerides was high $(\geq 150 \mathrm{mg} / \mathrm{dL}$ ) in 114 (46.53\%), Low Density Lipoprotein Cholesterol (LDL-C) was high ( $\geq 100 \mathrm{mg} / \mathrm{dL})$ in 112 (45.71\%) and High Density Lipoprotein Cholesterol (HDL-C) was low ( $\leq 40 \mathrm{mg} / \mathrm{dL})$ in 207 (84.49\%).

\section{OCCURRENCE AND SEVERITY OF AUTONOMIC DYSFUNCTION}

Autonomic dysfunction was detected in 174 (71.02\%) patients. Among them 144 (58.78\%) had mild autonomic dysfunction and 30 (12.24\%) had moderate autonomic dysfunction. No patients in our study had severe autonomic dysfunction.

Parasympathetic dysfunction was more common than sympathetic dysfunction (68.16\% vs. $17.96 \%)$. Among the tests, heart rate variation in deep inspiration and expiration (HEXIN) was abnormal in most of the patients (Table 2).

\section{ASSOCIATION OF AUTONOMIC DYSFUNCTION WITH DURATION AND OTHER BASELINE VARIABLES}

The severity of autonomic dysfunction was compared with duration of diabetes and other baseline variables to find their association. No statistically significant association was found either with duration or with any other baseline variables studied (Table 3). For duration of diabetes, analysis was done by taking five years and 10 years as cut-off points. No statistically significant result was found in either of the category (Table 4).

Table 1: Baseline variables of patients according to the duration of diabetes mellitus

\begin{tabular}{|c|c|c|c|c|}
\hline Variables & $\begin{array}{l}\text { Duration }<5 \text { years } \\
\qquad(n=91)\end{array}$ & $\begin{array}{l}\text { Duration } \geq 5 \text { years } \\
\qquad(n=154)\end{array}$ & Overall $(n=245)$ & $p$ value \\
\hline Age (years), Mean $\pm S D$ & $52 \pm 11$ & $58 \pm 9$ & $56 \pm 11$ & 0.079 \\
\hline Sex, Male: Female & $48: 43$ & $85: 69$ & $133: 112$ & 0.71 \\
\hline Body Mass Index (kg/m²) & $26.03 \pm 3.75$ & $26.31 \pm 1.5$ & $26.21 \pm 2.50$ & 0.260 \\
\hline Tobacco Smokers & $10(11 \%)$ & $25(16 \%)$ & 35 (14.29\%) & 0.257 \\
\hline Alcohol consumers & $24(26 \%)$ & $34(22 \%)$ & $58(23.67 \%)$ & 0.445 \\
\hline Hypertensives & $59(64 \%)$ & $105(68 \%)$ & $164(66.94 \%)$ & 0.591 \\
\hline Total cholesterol (mg\%), Mean \pm SD & $183 \pm 36.5$ & $177 \pm 39.08$ & $179.23 \pm 38.14$ & 0.977 \\
\hline LDL-C* (mg\%), Mean \pm SD & $102.53 \pm 35.22$ & $101.31 \pm 32.02$ & $101.76 \pm 33.24$ & 0.105 \\
\hline $\mathrm{HDL}-\mathrm{C}^{\dagger}(\mathrm{mg} \%)$, Mean $\pm \mathrm{SD}$ & $46 \pm 7.5$ & $46.77 \pm 12$ & $46.48 \pm 10.55$ & 0.147 \\
\hline Triglycerides (mg\%), Mean \pm SD & $175.73 \pm 89$ & $169.13 \pm 78.01$ & $171.58 \pm 82.26$ & 0.238 \\
\hline
\end{tabular}

$p$ value calculated by t-test.

*Low Density Lipoprotein Cholesterol

${ }^{\dagger}$ High Density Lipoprotein Cholesterol 
Karki DB et al.

Table 2: Positive test results

\begin{tabular}{lc}
\hline Tests & Positive results* $(\mathbf{n = 2 4 5 )}$ \\
Tests of Parasympathetic Dysfunction & $167(68.16 \%)$ \\
$\quad$ RHR $^{\dagger}$ & $21(8.57 \%)$ \\
HEXIN $^{\ddagger}$ & $117(47.76 \%)$ \\
VR $^{\S}$ & $71(28.98 \%)$ \\
$\quad$ RRIR $^{\Uparrow}$ & $36(13.69 \%)$ \\
Tests of Sympathetic Dysfuntion & $44(17.96 \%)$ \\
Postural Hypotension & $9(3.67 \%)$ \\
HGT & $37(15.1 \%)$ \\
\hline
\end{tabular}

*One person may have more than one test positive.

${ }^{\dagger}$ Resting heart rate

${ }^{*}$ Heart rate variability in deep expiration and inspiration

${ }^{\S}$ Valsalva ratio

\$30:15 RR interval ratio

**Hand grip test

Table 3: Association of Autonomic Dysfunction with various baseline variables

\begin{tabular}{|c|c|c|c|c|}
\hline Variables & $\begin{array}{c}\text { Normal Autonomic } \\
\text { Function }\end{array}$ & $\begin{array}{l}\text { Mild Autonomic } \\
\text { Dysfunction }\end{array}$ & $\begin{array}{c}\text { Moderate } \\
\text { Autonomic } \\
\text { Dysfunction }\end{array}$ & p value \\
\hline \multicolumn{5}{|l|}{ Age } \\
\hline$<40$ years $(n=16)$ & $6(37.5 \%)$ & $8(50 \%)$ & $2(12.5 \%)$ & 0.721 \\
\hline$\geq 40$ years $(n=229)$ & $65(28.4 \%)$ & $136(59.4 \%)$ & $28(12.2 \%)$ & \\
\hline \multicolumn{5}{|l|}{ Sex } \\
\hline Male $(n=133)$ & $40(30.2 \%)$ & 79 (59.3\%) & $14(10.5 \%)$ & 0.656 \\
\hline Female $(n=112)$ & $31(27.7 \%)$ & $65(58 \%)$ & $16(14.3 \%)$ & \\
\hline Smokers $(n=35)$ & $10(28.6 \%)$ & $21(60 \%)$ & $4(11.4 \%)$ & 0.983 \\
\hline Non-smokers $(n=210)$ & $61(29 \%)$ & $123(58.6)$ & $26(12.4 \%)$ & \\
\hline Alcohol Consumers $(n=58)$ & $18(31 \%)$ & 31 (53.4\%) & $9(15.6 \%)$ & 0.570 \\
\hline Non consumers $(n=187)$ & $53(28.3 \%)$ & $113(60.4 \%)$ & $21(11.3 \%)$ & \\
\hline \multicolumn{5}{|l|}{$B M I^{*}\left(\mathbf{k g} / \mathbf{m}^{2}\right)$} \\
\hline$<25(\mathrm{n}=109)$ & $33(30.2 \%)$ & $66(60.5 \%)$ & 10 (9.2\%) & 0.421 \\
\hline$\geq 25(n=136)$ & $38(30 \%)$ & $78(57.3 \%)$ & $20(14.7 \%)$ & \\
\hline \multicolumn{5}{|l|}{ Hypertension } \\
\hline Present $(n=164)$ & $45(27.4 \%)$ & $96(58.5 \%)$ & $23(14 \%)$ & 0.429 \\
\hline Absent $(n=81)$ & $26(32 \%)$ & $48(59.25 \%)$ & $7(8.75 \%)$ & \\
\hline \multicolumn{5}{|l|}{ Lipids } \\
\hline \multicolumn{5}{|l|}{ Total cholesterol } \\
\hline Normal $<200 \mathrm{mg} \%(\mathrm{n}=187)$ & $54(28.9 \%)$ & $110(58.8 \%)$ & $23(12.3 \%)$ & 0.997 \\
\hline High $\geq 200$ mg\% $(n=58)$ & $17(29.3 \%)$ & 34 (58.6\%) & $7(12.1 \%)$ & \\
\hline \multicolumn{5}{|l|}{ Triglyceride } \\
\hline Normal <150mg\% $(n=131)$ & $41(31.3 \%)$ & $74(56.5 \%)$ & $16(12.2 \%)$ & 0.679 \\
\hline High $\geq 150$ mg\% $(n=114)$ & $30(26.3 \%)$ & $70(61.4 \%)$ & $14(12.3 \%)$ & \\
\hline \multicolumn{5}{|l|}{ LDL-C $C^{\dagger}$} \\
\hline Normal <100mg\% $(n=133)$ & $42(31.3 \%)$ & $74(55.6 \%)$ & $17(12.8 \%)$ & 0.540 \\
\hline High $\geq 100 m g \%(n=112)$ & $29(25.9 \%)$ & $70(62.5 \%)$ & $13(11.6 \%)$ & \\
\hline \multicolumn{5}{|l|}{ HDL-C $C^{\ddagger}$} \\
\hline Normal >40mg\% $(n=38)$ & $8(21 \%)$ & $25(65.8 \%)$ & $5(13.2 \%)$ & 0.501 \\
\hline Low $\leq 40 \mathrm{mg} \%(\mathrm{n}=207)$ & $63(30.4 \%)$ & $119(57.5 \%)$ & $25(12.1 \%)$ & \\
\hline
\end{tabular}

$p$ value calculated by chi-square test.

*Body Mass Index, 'Low Density Lipoprotein Cholesterol, ${ }^{*}$ High Density Lipoprotein Cholesterol 
Table 4: Relation of Autonomic Dysfunction with Duration of Diabetes

\begin{tabular}{lcc}
\hline Duration & $\begin{array}{c}\text { Number of patients with autonomic } \\
\text { dysfunction }\end{array}$ & p value \\
$<5$ years $(n=91)$ & $69(75.8 \%)$ & 0.203 \\
$\geq 5$ years $(n=154)$ & $105(68.2 \%)$ & 0.865 \\
$<10$ years $(n=171)$ & $122(71.3 \%)$ & \\
$\geq 10$ years $(n=74)$ & $52(70.2 \%)$ & \\
\hline
\end{tabular}

$p$ value calculated by t-test.

\section{DISCUSSION}

This study shows that autonomic dysfunction is quite common (71.02\%) among Type 2 diabetic patients and that its prevalence is not associated with duration of disease.

The baseline variables (age, sex, hypertension, smoking, alcohol consumption, dyslipidaemia, obesity) were distributed equally among those with duration of disease less than five years and those with the duration five years or more.

Various studies have shown the prevalence of autonomic dysfunction to be from eight percent to $90 \%{ }^{17,19}$. Duration of disease and extent of glycaemic control are two important determinants in development of autonomic dysfunction in both type 1 and type 2 diabetes. In type 1 diabetes, this complication is usually seen after eight to10 years of diagnosis, whereas in type 2 diabetes, it may be seen earlier on or even at the time of diagnosis'. This study shows the overall prevalence of autonomic dysfunction among type 2 diabetics to be $71.02 \%$. Even among those with diabetes diagnosed for less than five years, three fourths (75.82\%) already had this complication.The prevalence does not seem to be associated with duration. Even after categorization into duration less than 10 years and 10 or more years, we found no statistically significant difference in prevalence of autonomic dysfunction. Besides the duration of disease, poor glycaemic control might have contributed to high prevalence of autonomic dysfunction in our study. Timely and adequate control of blood sugar level is needed in order to prevent or delay its progression. This study, however, does not analyse the glycaemic control among the participants, which is a major limitation of this study.

Parasympathetic nervous system is involved early and is followed by sympathetic nervous system. Studies have confirmed the presence of parasympathetic dysfunction in $65 \%$ of type 2 diabetic patients 10 years after diagnosis and of combined parasympathetic and sympathetic neuropathy in $15.2 \%{ }^{18}$. Abnormality of heart rate during deep breathing is the first sign among the tests of autonomic dysfunction. We have found similar results in this study. Parasympathetic dysfunction was present in $68.16 \%$ whereas sympathetic dysfunction was present in $17.96 \%$. HEXIN alone was positive in nearly half of patients.

Autonomic dysfunction affects virtually all organ systems including cardiovascular, gastrointestinal, genitourinary, metabolic, sudomotor, and pupillary functions ${ }^{20}$. Complications like hypoglycaemia unawareness, nocturnal fall in blood pressure with myocardial hypoperfusion, silent myocardial ischaemia and arrhythmias can produce lethal outcomes. Thus, early diagnosis and timely intervention is important. Patients with sympathetic over-activity as a result of predominant parasympathetic involvement may be advised long term beta blockers to reduce incidence of arrhythmias and sudden death. Mild postural symptoms can be treated by discontinuation of drugs i.e. tranquilizers, antidepressants, antidiuretic and elevation of head of bed by up to $30 \mathrm{~cm}^{21}$, Alpha adrenoreceptor agonist Midodrine, beta-blockers with intrinsic sympathomimetic activity, Fluoxetine or Desmopressin have been tried in the treatment of postural hypotension ${ }^{22,23}$. Treatment of autonomic neuropathy is possible with Azathioprine or Prednisolone. Intravenous immunoglobulin and plasmapheresis are other modalities of treatment of severe autoimmune autonomic neuropathies. Fludrocortisone can be given in postural hypotension and frequent small low carbohydrate meals are advised. How these treatments are effective in diabetic patients are not clear. Patients having Diabetic autonomic neuropathy are advised regular physical exercise. Exercise programme can improve both early and more advanced cardiovascular autonomic neuropathy ${ }^{24,25}$. These measures, however, are of limited benefit and proper glycaemic control seems to be the best way to prevent or delay this complication. 
Our study is unique as it is one of the few studies done in autonomic dysfunction in Nepal. We have shown the simplicity of doing the test and highlighted the importance of early diagnosis of this condition. A more conclusive explanation for non-relation between duration of diabetes and occurrence of autonomic dysfunction could have been obtained if extent of glycaemic control was also evaluated. Moreover, being a hospital based study, it suffers from the inherent Berkesonian bias. Larger population based studies could provide a better insight into this problem.

\section{CONCLUSION}

Autonomic neuropathy is very common in diabetics. ANSEV is a non-invasive and very useful investigation and should be undertaken in all diabetic patients for early detection of this condition.

\section{ACKNOWLEDGEMENT}

Authors are thankful to Mrs Kalpana Joshi for assisting in evaluation of autonomic nervous system evaluation tests and to Dr. Surakshya Joshi for helping in editing the manuscript.

\section{REFERENCES}

1. Powers AC. Diabetes mellitus. In: Longo DL, Fauci AS, Kasper DL, Hauser SL, Jameson JL, Lozcalzo J, editors. Harrison's Principles of Internal Medicine. 18th ed. Vol. 2. USA: McGraw-Hill; 2012. p. 29683003.

2. Gaede $P$, Vedel P, Larsen N, Jensen GV, Parving $\mathrm{HH}$, Pedersen O. Multifactorial intervention and cardiovascular disease in patients with type 2 diabetes. N Engl J Med. 2003 Jan 30; 348(5):383-93.

3. Veglio M, Borra M, Stevens LK, Fuller JH, Perin PC. The relation between QTc interval prolongation and diabetic complications. The EURODIAB IDDM Complication Study Group. Diabetologia. 1999 Jan;42(1):68-75.

4. Ziegler D. Cardiovascular autonomic neuropathy: clinical manifestations and measurement. Diabetes Reviews. 1999;7:342.

5. Cohen JA, Estacio RO, Lundgren RA, Esler AL, Schrier RW. Diabetic autonomic neuropathy is associated with an increased incidence of strokes. Auton Neurosci. 2003 Oct 31;108(1-2):73-8.

6. Bottini $\mathrm{P}$, Redolfi $\mathrm{S}$, Dottorini ML, Tantucci C. Autonomic neuropathy increases the risk of obstructive sleep apnea in obese diabetics. Respiration. 2008;75(3):26-71.

7. Hornung RS, MahlerRF, Raftery EB. Ambulatory blood pressure and heart rate in Diabetic patients: an assessment of autonomic function. Diabet Med. 1989;6:579-85.

8. Stevens MJ, Edmonds ME, Mathias CJ, Watkins PJ. Disabling postural hypotension complicating Diabetic autonomic neuropathy. Diabet Med. 1991;8:870-4.

9. Edmonds ME, Nicolaides K, Watkins PJ. The importance of autonomic neuropathy in the etiology of Diabetic neuropathic foot ulceration. Diabetologia. 1981;21:506.

10. Ryder RE, Kennedy RL, Newrick PG, Wison RM, Ward JD, Hardisty CA. Autonomic denervation may be a

prerequisite of Diabetic neuropathic foot ulceration. Diabet Med. 1990 Sep;7(8):726-30.

11. Edmonds ME, Archer AG, Watkins PJ. Ephedrine: a new treatment for Diabetic neuropathic oedema. Lancet. 1983 Mar 12:548-51.

12. Ewing DJ, Clark BF. Diagnosis and management of diabetic autonomic neuropathy. $\mathrm{Br}$ Med J. 1982;285:916-8.

13. Low PA, Denq JC, Opfer-Gehrking TL, Dyck PJ, O'Brien PC, Slezak JM, Effect of age and gender on sudomotor and cardiovagal function and blood pressure response to tilt in normal subjects. Muscle Nerve. 1997 Dec;20(12):1561-8.

14. Freeman R. Heart rate variability - the time domain. In: Low PA, editor. Clinical Autonomic Disorders. Boston:Little Brown; 1997. p.297.

15. Freeman R, Cohen RJ, Saul JP. Transfer function analysis of respiratory sinus arrhythmia: a measure of autonomic function in diabetic neuropathy. Muscle Nerve. 1995 Jan;18(1):74-84.

16. Mackay JD. Respiratory sinus arrhythmia in diabetic neuropathy. Diabetologia. 1983 Apr;24(4):253-6.

17. Borst C, Wieling W, van Brederode JF, Hond A, de Rijk LG, Dunning AJ. Mechanisms of initial heart rate response to postural change. Am J Physiol. 1982 Nov;243(5):H676-81.

18. The Diabetes Control and Complications Trial Research Group. The effects of intensive diabetes therapy on measures of autonomic nervous system function in the Diabetes Control and Complications Trial (DCCT). Diabetologia. 1998;41:416-23.

19. Aring $A M$, Jones $D E$, Falko JM. Evaluation and prevention of diabetic neuropathy. Am Fam Physician. 2005;71:2123-8.

20. Vinik Al, Mitchell BD, Maser RI, Freeman R. Diabetic autonomic neuropathy (Technical Review). Diabetes Care. 2003 May;26(5):1553-79.

21. Vinik Al, Ziegler D. Diabetic cardiovascular autonomic neuropathy. Circulation. 2007; 115:387. 
22. Bernardi L, Ricordi L, Lazzari P, Solda P, Calciati A, Ferrari MR. Impaired circadian modulation of sympathovagal activity in Diabetes. A possible explanation for altered temporal onset of cardiovascular disease. Circulation. 1992 Nov;86(5):1443-52.

23. Fouad-Tarazi, FM, Okabe, M, Goren, H. Alpha sympathomimetic treatment of autonomic insufficiency with orthostatic hypotension. Am J Med. 1995;99:604.
24. Howorka K, Pumprla J, Haber P, Koller-Strametz J, Mondrzykr J, Schabmann A. Effects of physical training on heart rate variability in Diabetic patients with various degrees of cardiovascular autonomic neuropathy. Cardiovasc Res. 1997 Apr;34(1);206-14.

25. Pagkalos M, Koutlianos N, Kouidi E, Pagkalos E, Mandroukas K, Deligiannis A. Heart rate variability modifications following exercise training in type 2 Diabetic patients with definite cardiac autonomic neuropathy. Br J Sports Med. 2008 Jan;42(1):47-54. 